\title{
A New Arc-Based Model and Condition Monitoring Algorithm for On-Load Tap-Changers
}

\author{
Behnam Feizifar, Omer Usta* \\ Department of Electrical Engineering, Istanbul Technical University \\ Istanbul, Turkey
}

\begin{abstract}
An on-load tap-changer (OLTC) regulates the output voltage level of transformer by changing the winding voltage ratio without current interruption. It is one of the most expensive and vulnerable parts of power transformers. Therefore, modeling and condition monitoring (CM) of OLTCs are important for the power system operation. This paper presents a new modeling principle for OLTCs based on the circuit breaker (CB) arc models. There is a sequence of switching events with certain timings during each operation of OLTC. These switching operations are modeled individually and a full model of OLTC operation is derived. On the other hand, the instantaneous differential power of tap-changing transformer measured from its input and output terminals is used to calculate the arcing power and energy associated with OLTC operation. The cumulative arcing energy is a good indication of the electrical wear of OLTC contacts. Therefore, it is used to propose a novel CM algorithm for OLTCs. The proposed method considers the effects of both arcing voltage and current signals to accurately estimate the arcing energy. The results obtained from computer simulation studies demonstrate that the proposed algorithm accurately evaluates the electrical wear of OLTC contacts and determines the inspection or maintenance schedules of OLTC contacts. The measurements captured from the real-time test studies of OLTC operation verify and validate the performance of the proposed OLTC model.
\end{abstract}

Keywords: Arcing power, arcing energy, circuit breakers, condition monitoring, contact degradation, on-load tap-changers.

\section{Introduction}

On-load tap-changers (OLTCs) are considered as electro-mechanical switching equipment operating within tap-changing transformers. The operational principle of

\footnotetext{
* Corresponding author. Department of Electrical Engineering, Istanbul Technical University, Maslak-34469, Istanbul, Turkey, Tel.: +90 212 2856755; Fax: +90 2122856700.

E-mail address: usta@ieee.org (O. Usta)
} 
OLTCs is based on a sequence of switching events within certain timing intervals. The final target of these switching events is to change the transformer ratio using tapped windings to compensate over and under voltages originated from load variations [1].

The safe and reliable operation of power transformers is very essential in minimizing the number of power system outages. According to international surveys, OLTCs are responsible for the majority of transformer failures [2], [3]. OLTC is one of the most expensive and vulnerable parts of power transformers. Therefore, its operating conditions have to be continuously monitored. Many condition monitoring (CM) methods have been proposed and developed with respect to OLTCs in the literature.

The single-phase exciting-current test is an off-line technique and has been implemented to identify different problems within tap-changing transformers [4]. Furthermore, the dissolved gas-in-oil analysis (DGA) has been utilized for the CM of OLTC by analyzing different gases in OLTC compartment produced during operating conditions and it can be executed using off-line and on-line techniques [5].

The majority of available CM methods for OLTCs are based on vibration monitoring. In this manner, several signal analysis and data classification methods have been used such as wavelet transform (WT) that includes the continuous wavelet transform (CWT) and discrete wavelet transform (DWT) [6], [7]; self-organizing map (SOM) [8], [9]; the combination of WT and SOM [10]; the combination of WT and Hilbert transform [11], [12]; analysis of chaotic dynamic feature [13]; the combination of chaos theory and fuzzy c-means algorithm [14], [15]; fractal geometry [16], [17]; genetic algorithm (GA) [18]; the hidden Markov model (HMM) [19]; time-frequency analysis [20].

The combination of vibration measurement and arcing signal analysis has been also proposed [21]. Arcing signal has been be measured by a split core high frequency current transformer which is mounted on the grounding cable of power transformer.

Dynamic resistance measurement (DRM) technique has been also used for failure detection and contact erosion identification of OLTCs [22], [23]. A chromatic analysis of acoustic signals using the optical fiber sensor has been also proposed [24]. The mounting location of sensors must be as close as possible to the OLTC on the tank of tap-changing transformer. In addition, the combination of the motor current signature and vibro-acoustic measurement has been utilized for the CM of OLTCs [25].

Electrical wear of contacts occurs due to the high temperature of electric arc events, 
which in return produces power or energy loss. Therefore, not only arcing currents but also arcing voltages are behind the electrical wear of contact. The authors have recently introduced an arcing power-based CM algorithm for circuit breakers (CBs) in which the correlation between the cumulative arcing energy and the electrical wear of CB contacts has been demonstrated [26]. On the other hand, several power-based digital protection algorithms have been successfully applied to the loss of utility grid supply, islanding, pole slipping, and protection against asymmetrical faults of generators [27]-[29].

This paper introduces a novel modeling principle for OLTCs based on the CB arc models as its first contribution. The second contribution of the paper is a new powerbased algorithm for the CM of OLTCs using the measurements of power loss due to the arcing event and the related energy that can be implemented in a real-time framework.

\section{Modeling of On-Load Tap-Changers Using Circuit Breaker Arc Models}

Up to the present time, there is no arc-based model in the literature to represent the OLTC operation. The existing electrical models of OLTC regulating transformers can only simulate the tap-changing operations as ideal switching events [30]-[31].

Therefore, this section deals with the arc modeling of OLTCs. The operating mechanism of OLTCs is based on a sequence of switching events in order to change the winding turn's ratio of transformer and the ultimate target of OLTC is to change the transformer voltage ratio without interrupting load currents that is called "make-before-

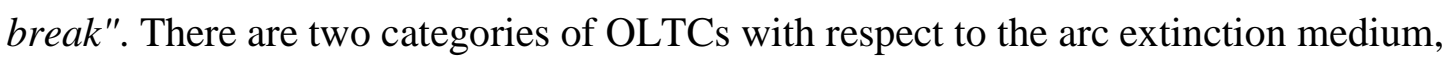
namely, the oil-type and the vacuum-type OLTCs. Another classification is based on the current-limiting elements. In this regard, both the resistor-type and reactor-type transition elements can be used in order to reduce the temporary circulating current. In this paper, the resistor oil-type OLTC is considered, because it needs more frequent maintenance compared to the vacuum-type. In the oil-type OLTC, there are two switching principles for changing the tap position which are the selector switch-type (arcing tap switch) and the diverter switch-type (arcing switch).

Fig. 1 illustrates the sequence of changing the tap position from 3 to 2 in a diverter switch-type OLTC. In this figure, the contacts " $a$ " and " $d$ " are known as the main switching contacts (MSCs) and the contacts " $b$ " and " $c$ " indicate the transition contacts (TCs). The transition resistors are utilized to prevent a momentary short circuit during the tap-changing process. 
The diverter switch-type of OLTC works with a tap selector and is designed for higher ratings and voltages, whereas in the selector switch-type of OLTC, the function of both diverter and selector switches is integrated in a selector switch and it is used for lower ratings and voltages.

Fig. 2 shows the timing sequence of switching operations for changing the tap position from 3 to 2 that is applicable for both diverter switch and selector switch designs. In this figure, there are three overlaps between MSCs and TCs. The tapchanging process starts at time zero and the entire switching operations are completed in about $60 \mathrm{~ms}$. The entire process executes one step tap-changing operation in the transformer winding. The first overlap is between " $a$ " and " $b$ " and the last overlap is between " $c$ " and " $d$ ". The first and the last overlaps are not very critical because the voltage level does not change in these positions. The middle overlap is between " $b$ " and " $c$ ", namely between two TCs. This position is of great importance because the voltage level changes in this step and the OLTC circulating current flows through transition resistors and two adjacent steps of tap-changing transformer.

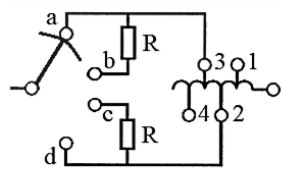

(1)

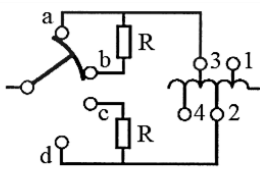

(2)

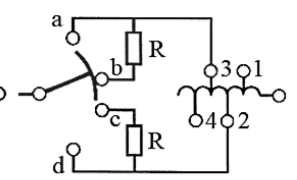

(3)

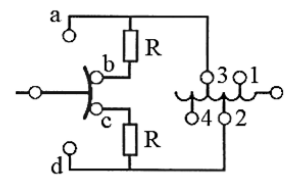

(4)

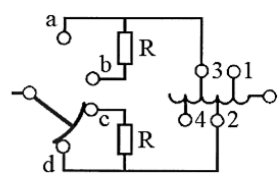

(6)

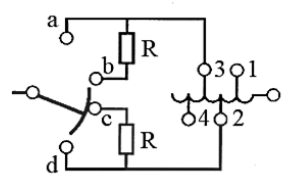

(5)

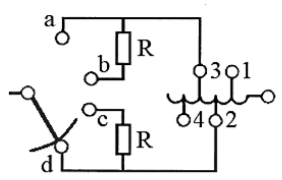

(7)

Fig. 1. Changing the tap position from 3 to 2 in a diverter switch-type OLTC.

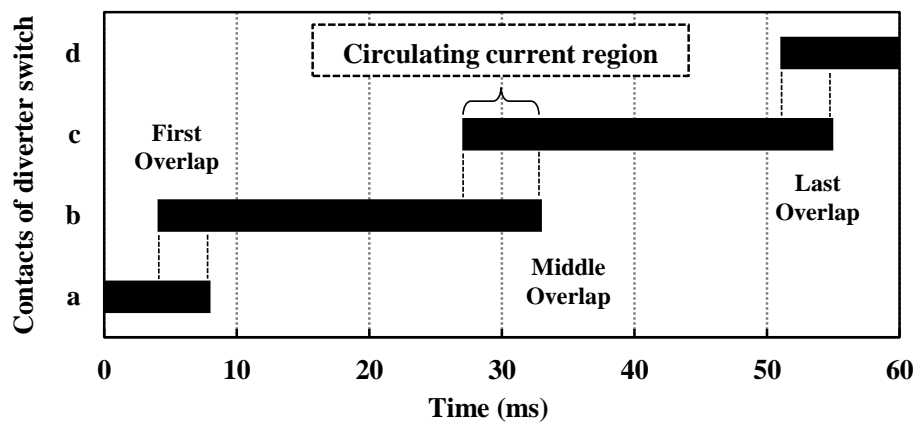

Fig. 2. Timing sequence of the contacts of the OLTC diverter switch. 
Based on the above expressions, a new modeling concept for the OLTC switching operations has been proposed that uses the CB arc models.

There are basically two arc models that are the foundation of other extended models. The first model has been proposed by A. M. Cassie in 1939 [32]. This model considers an arc channel with constant quantities of current density, electric field intensity, and temperature. The second arc model has been proposed by O. Mayr in 1943 [33]. In this model, the temperature is changing but the size and the shape of arc column are considered as constant.

Consequently, the combination of these arc models can accurately represent the arc transient behavior in both high and low current regions as a generalized arc model [34].

The generalized arc model has been utilized for modeling the CB nonlinear conductance. A transient recovery voltage (TRV) adjusting branch has been also utilized in parallel with the arc conductance to model the transient oscillations occurring after arc extinction. The electrical circuit of CB model is shown in Fig. 3 [35].

The CB model has been used to represent the MSCs and TCs of OLTC and thus an original model of OLTC is introduced as depicted in Fig. 4. The proposed OLTC model is in the primary side of tap-changing transformer. Each contact of OLTC is represented by the CB model along with two transition resistors in series with two TCs.

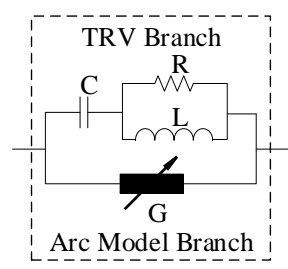

Fig. 3. A CB model utilizing the series connection of Cassie-Mayr arc conductances $(G)$ in parallel with the TRV controlling branch.

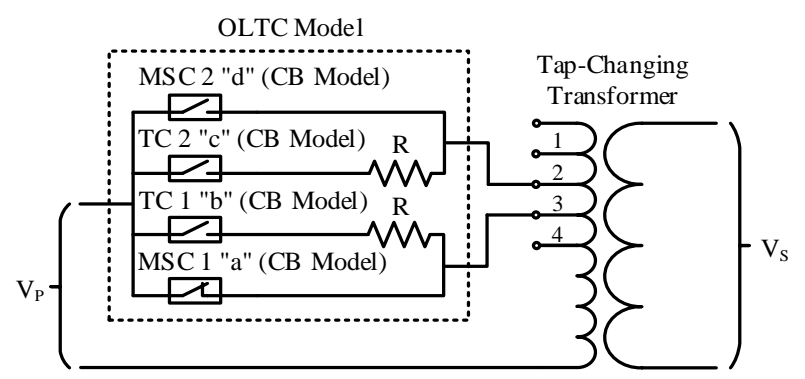

Fig. 4. Proposed OLTC model by integrating four CB models to represent the OLTC MSCs and TCs in a tap-changing transformer.

In Fig. 4, a tap-changing operation between the tap position 3 and 2 is executed. The timing sequence of OLTC operation was noted earlier in Fig. 2. The transient analysis 
of control system (TACS) module within the electro-magnetic transient program restructured version (EMTP-RV) is used to implement the proposed model [36].

\section{Condition Monitoring of OLTC's Contact Wear}

\section{A. Number of operations or time of service (Constant counting-based algorithm)}

The easiest but not the most accurate CM method for OLTCs is based on number of tap changing operations or time of service as this is the case for CBs as well. In this technique, there is a threshold value defined by manufacturers for each specific type of OLTC at rated currents. For example, after every 80,000 operations or three years of service whichever comes first, the OLTC maintenance is essential. The OLTC maintenance includes the inspection of oil, mechanical and electrical wear of contacts. However, the serious weakness of this method is that it solely considers the constant mechanical wear of contacts and fully ignores the electrical wear of OLTC's contacts caused by different levels of load currents.

\section{B. Proposed arcing power-based CM method}

The proposed CM method for OLTC uses the arcing power and related arcing energy under different operating conditions. The instantaneous input power of transformer (i.e., $\left.p_{\text {in }}(t)\right)$ is measured using the input voltage (i.e., $\left.v_{\text {in }}(t)\right)$ and input current (i.e., $i_{\text {in }}(t)$ ) of transformer and the instantaneous output power of transformer (i.e., $p_{\text {out }}(t)$ ) can be easily captured utilizing the output voltage (i.e., $\left.v_{\text {out }}(t)\right)$ and output current (i.e., $\left.i_{\text {out }}(t)\right)$ of transformer as follows,

$$
\begin{gathered}
p_{\text {in }}(t) \triangleq v_{\text {in }}(t) i_{\text {in }}(t) \\
p_{\text {out }}(t) \triangleq v_{\text {out }}(t) i_{\text {out }}(t)
\end{gathered}
$$

The instantaneous differential power between the input and output of transformer can be calculated as follows,

$$
\begin{gathered}
\qquad p(t)=p_{\text {in }}(t)-p_{\text {out }}(t) \\
\text { Under normal operating condition } \rightarrow \Delta p(t)=p_{\text {loss }} \\
\text { Under tap changing condition } \rightarrow p_{\text {arc }}=\Delta p(t)-p_{\text {loss }}-p_{R_{t}}
\end{gathered}
$$

where, $p_{\text {loss }}$ is the transformer power loss, $p_{R_{t}}$ is the power loss on the OLTC transition resistors, $p_{\text {arc }}$ is the arcing power originated by tap-changing operation. 
Based on equations (3), (4), and (5), the instantaneous differential power of transformer is always equal to the internal power loss except during tap-changing operation in which the OLTC arcing power (power loss due to the arcing event) also integrates to the instantaneous differential power. Thereby, the arcing powers of the OLTC operations can be calculated for different operating conditions using equations (1) to (5). This process does not need to be synchronized to power system frequency. The issue of time/frequency synchronization is very concerning especially during power system transient conditions. The problem is that it requires an advanced filtering and hence a high computation time for a successful synchronization.

The proposed arcing power-based CM algorithm for OLTCs is explained in details by the following steps.

\section{1) Measurement of instantaneous differential power}

The voltage and current signals of input and output terminals of power transformer are measured using digitalized samples. The numerical implementations of equations (1), (2), and (3) can be performed using the following formulas in order to calculate the instantaneous power difference between the terminals of power of transformer,

$$
\begin{gathered}
p_{\text {in }}\left[s T_{s}\right] \triangleq v_{\text {in }}\left[s T_{s}\right] i_{\text {in }}\left[s T_{s}\right] \\
p_{\text {out }}\left[s T_{s}\right] \triangleq v_{\text {out }}\left[s T_{s}\right] i_{\text {out }}\left[s T_{s}\right] \\
\Delta p\left[s T_{s}\right]=p_{\text {in }}\left[s T_{s}\right]-p_{\text {out }}\left[s T_{s}\right]
\end{gathered}
$$

where, $s$ is the sampling rate and $T_{s}$ is the sampling period.

\section{2) Estimation of transformer power loss}

The instantaneous power loss of transformer under different operating conditions can be estimated using the combination of scaling equations as follows [37],

$$
\begin{aligned}
p_{\text {loss }}\left[s T_{s}\right]= & P_{F e(n l)} \times\left(\frac{v_{\text {out }}\left[s T_{s}\right]}{v_{\text {out }(\text { rated })}\left[s T_{s}\right]}\right)^{2}+P_{C u(f l)} \times\left(\frac{i_{\text {in }}\left[s T_{s}\right]}{i_{\text {in }(\text { rated })}\left[s T_{s}\right]}\right)^{2}+ \\
& Q_{F e(n l)} \times\left(\frac{v_{\text {out }}\left[s T_{s}\right]}{v_{\text {out }(\text { rated })}\left[s T_{s}\right]}\right)^{4}+Q_{C u(f l)} \times\left(\frac{i_{\text {in }}\left[s T_{s}\right]}{i_{\text {in }(\text { rated })}\left[s T_{s}\right]}\right)^{2}
\end{aligned}
$$

where, $P_{F e(n l)}$ and $Q_{F e(n l)}$ are the active and reactive iron or core losses obtained from no-load test; $P_{C u(f l)}$ and $Q_{C u(f l)}$ are the active and reactive copper losses calculated by full-load test; the input index indicates the high-voltage side and the 
output index is the low-voltage side of transformer (i.e., a step-down transformer has been assumed in this paper). In case of having a step-up transformer, the input and output indices in equation (9) must be substituted because the metering sides of no-load and full-load tests will be changed accordingly.

3) Estimation of power loss on the OLTC transition resistors

The power loss on the OLTC transition resistors can be estimated as follows,

$$
p_{R_{t}}\left[s T_{s}\right]=\frac{v_{\text {step }}^{2}\left[s T_{s}\right]}{2 \times R_{t}}
$$

where, $V_{\text {step }}$ is the instantaneous step voltage of OLTC and $R_{t}$ is the OLTC transition resistance defined by manufacturers.

4) Calculation of arcing power (Power loss due to arcing incident)

The arcing power of OLTC under tap-changing condition can be calculated as follows,

$$
p_{\text {arc }}\left[s T_{s}\right]=\Delta p\left[s T_{s}\right]-p_{\text {loss }}\left[s T_{s}\right]-p_{R_{t}}\left[s T_{s}\right]
$$

where, $\Delta p$ is the instantaneous differential powers under tap-changing conditions and $p_{\text {loss }}$ is the instantaneous power loss, and $p_{R_{t}}$ is the power loss on the OLTC transition resistors.

\section{5) Moving average of arcing power}

A moving average filter performs an averaging on input data sequence to have a smooth output data sequence. In this regard, certain number of points are taken from input data to produce output data points. Thus, the moving average of arcing power of transformer can be expressed as follows [38],

$$
p_{M A}\left[s T_{s}\right]=\frac{1}{N} \sum_{j=N-1}^{0} p_{a r c}\left[s T_{s}+j T_{s}\right]
$$

where, $N$ is the window length of the filter; $j$ is the sampling index of the arcing power of transformer; $p$ is the arcing power of transformer; $p_{M A}$ is the moving average of the arcing power of transformer.

Thereby, the moving average filter effectively removes high frequency components and provides a smooth and more reliable instantaneous power signal for the proposed 
algorithm.

\section{6) Condition monitoring threshold value}

The CM threshold value that remains constant within the CM process needs to be initially determined for each certain type of OLTC using following equation.

$$
E_{\text {thre }}=n_{\text {rated }} \times\left(\sum_{s=0}^{n-1} p_{M A(\text { rated })}\left[s T_{s}\right]\right)^{k}
$$

where, $n$ is the number of samples of instantaneous power, $n_{\text {rated }}$ is the number of permissible operations (i.e., without requiring the inspection or maintenance of OLTC contacts) at the rated step capacity of OLTC that is defined by manufacturer, $p_{M A \text { (rated }}$ is the moving average of the OLTC arcing power of transformer at the maximum rated step capacity of OLTC, and $k$ is the exponent value of the arcing power of transformer changing from 1.0 to 2.0 relating to the dielectric withstand of OLTC insulation defined by manufacturers. The dielectric withstand of oil decreases fast and therefore the exponent value is taken as 2.0 for oil-type OLTCs. For vacuum-type OLTCs, the exponent value is typically 1.5 [39].

Specifically, the alarm level of CM algorithm for the OLTC used in this study has been calculated as 11 MVA.s, as listed in Table 4.

\section{7) Condition monitoring alarm criteria}

The following formula accumulates the integrations or summations of the measured arcing powers (i.e., arcing energies) following each OLTC operation to calculate the cumulative arcing energy of tap-changing transformer as follows,

$$
E_{\text {sum }}=\sum_{i=1}^{m}\left(\sum_{s=0}^{n-1} p_{M A(i)}\left[s T_{s}\right]\right)^{k}
$$

where, $m$ is the number of tap-changing operations.

The CM alarm criteria is evaluated by comparing the cumulative arcing energy to the CM threshold value during each OLTC operation as follows,

$$
E_{\text {sum }}>E_{\text {thre }}
$$


Whenever the accumulated arcing energy exceeds the predefined threshold value, an alarm signal will be initiated by the CM algorithm to inform the system operator. This warning flag indicates that the maximum electrical wear of OLTC contacts is reached and the inspection or maintenance is necessary. Otherwise, the proposed CM algorithm continues to measure and accumulate the forthcoming arcing powers of transformer during next tap-changing operations. Fig. 5 shows the flowchart of the proposed CM procedure.

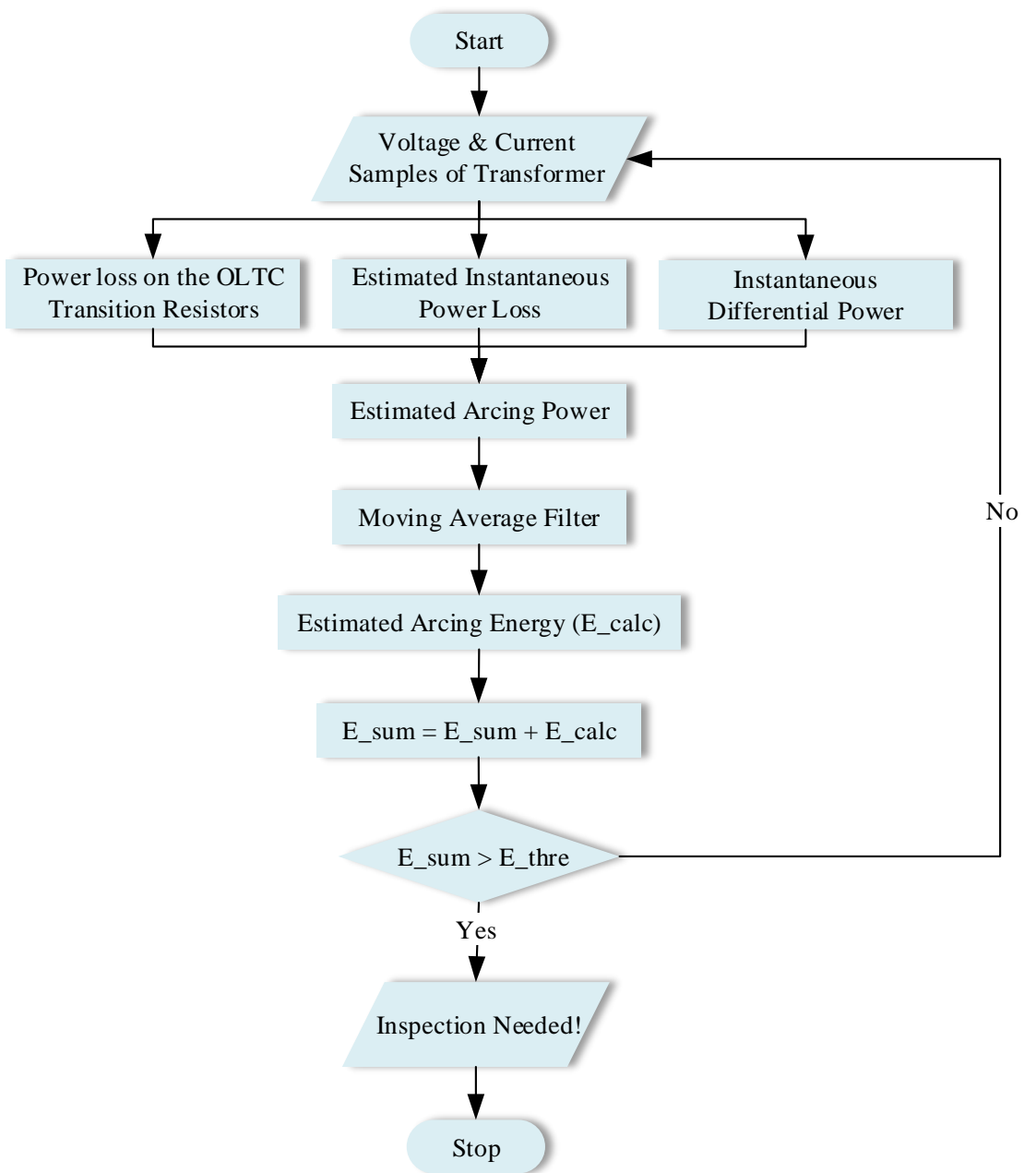

Fig. 5. Flowchart of the proposed CM algorithm for OLTCs.

\section{Computer Simulation Studies}

The simulation studies have been carried out to evaluate the performance of the proposed algorithm. A modification of the IEEE 13-bus balanced industrial distribution system excluding the local (in-plant) generator and the related auxiliary bus has been simulated in the EMTP-RV as illustrated in Fig 6 [40]. The main power transformer of the balanced industrial distribution test system (15 MVA, $69 \mathrm{kV} / 13.8 \mathrm{kV}$ ) has been 
equipped with the OLTC arc model. The technical specifications related to the main power transformer and its OLTC are listed in Table 1 and Table 2 [41], respectively.

Table 1: Technical specifications of the main transformer.

\begin{tabular}{cc}
\hline \hline Technical features & Description \\
\hline Power & $15 \mathrm{MVA}$ \\
Primary voltage & $69 \mathrm{kV}$ \\
Secondary voltage & $13.8 \mathrm{kV}$ \\
Impedance $\%$ & $8 \%$ \\
No-load active power loss $\left(\boldsymbol{P}_{\boldsymbol{F} e(\boldsymbol{n} \boldsymbol{l})}\right)$ & $10 \mathrm{~kW}$ \\
No-load reactive power loss $\left(\boldsymbol{Q}_{\boldsymbol{F} e(\boldsymbol{n} \boldsymbol{l})}\right)$ & $14 \mathrm{kVAR}$ \\
Full-load active power loss $\left(\boldsymbol{P}_{\boldsymbol{C u}(\boldsymbol{f l})}\right)$ & $28 \mathrm{~kW}$ \\
Full-load reactive power loss $\left(\boldsymbol{Q}_{\boldsymbol{C u}(\boldsymbol{f l})}\right)$ & $480 \mathrm{kVAR}$ \\
\hline \hline
\end{tabular}

Table 2: Technical specifications of the simulated OLTC.

\begin{tabular}{cc}
\hline \hline Technical features & Description \\
\hline OLTC type & High-speed resistor-type OILTAP \\
Max. rated through current & $350 \mathrm{~A}$ \\
Rated short-time withstand current & $5 \mathrm{kA}$ \\
Rated peak withstand current & $12.5 \mathrm{kA}$ \\
Max. rated step voltage & $1500 \mathrm{~V}$ \\
Max. rated step capacity & $525 \mathrm{kVA}$ \\
Rated frequency & $50 / 60 \mathrm{~Hz}$ \\
Highest operating voltage & $40 \mathrm{kV}$ \\
Transition resistances & $3 \Omega$ \\
\hline \hline
\end{tabular}

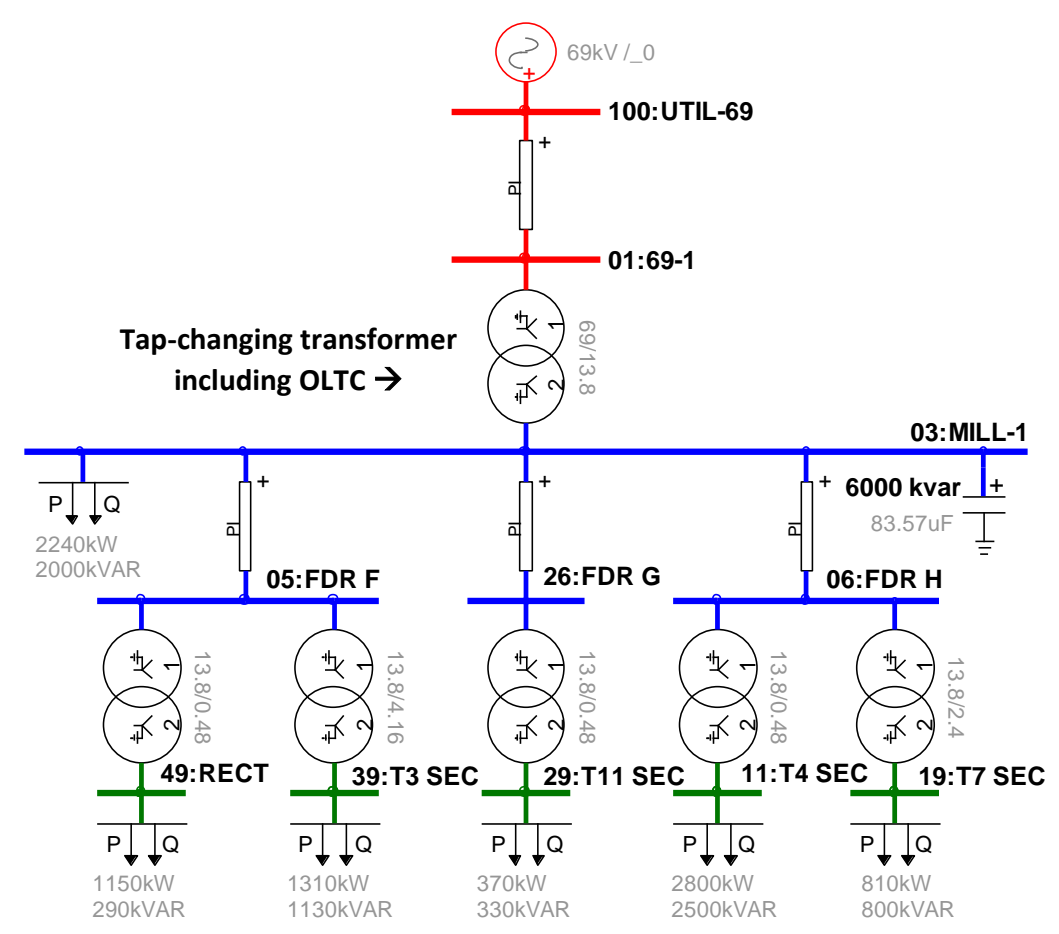

Fig. 6. A modification of the IEEE 13-bus balanced industrial distribution test system excluding the local (in-plant) generator and the related auxiliary feeder. 
Also, the constant parameters of the Cassie-Mayr arc model associated to each switching operation of OLTC are listed in Table 3 [42].

Table 3: Arc constant parameters of the simulated OLTC.

\begin{tabular}{ccc}
\hline \hline Arc Model Parameters & Cassie Model & Mayr Model \\
\hline Time constant $\left(\tau_{\mathrm{c}}, \tau_{\mathrm{m}}\right)$ & $12 \mu \mathrm{s}$ & $4 \mu \mathrm{s}$ \\
Constant power loss $\left(\mathrm{P}_{0}\right)$ & - & $2 \mathrm{MW}$ \\
Constant voltage $\left(\mathrm{v}_{0}\right)$ & $5 \mathrm{kV}$ & - \\
Initial conductance $\left(\mathrm{g}_{0}\right)$ & $1000 \mathrm{~S}$ & $1000 \mathrm{~S}$ \\
\hline \hline
\end{tabular}

These black-box arc parameters have been presumably considered for the OLTC. However, the actual arc parameters associated with each type of OLTC can be acquired using laboratory measurements. The resistance, inductance, and capacitance of the TRV branch of the CB model are considered as $0.5 \Omega, 1 \mu \mathrm{H}$, and $1.6 \mathrm{nF}$, respectively [34]. The step voltages of transformer winding have been considered as $1.5 \mathrm{kV}$ (i.e., the maximum permissible step voltage that can be applied between two adjacent contacts of OLTC). As the distribution test system is completely balanced, the entire simulation studies have been executed on single-phase base throughout the paper.

The industrial distribution system has a nominal frequency of $60 \mathrm{~Hz}$. The sampling frequency has been set to $1 \mathrm{MHz}$ and the total simulation period is $100 \mathrm{~ms}$. The length of the moving average window has been preselected as $10 \mathrm{~ms}$ which includes 10,000 samples. The exponent quantity $(k)$ in equations (13) and (14) has been considered as 2.0 for the investigated oil-type OLTC. However, it can be changed according to the dielectric withstand of OLTC insulations relating to different types of OLTCs defined by manufacturers. The number of permissible tap-changing operations at the maximum rated through current and rated step capacity has been set to 80,000 by the manufacturer according to the mechanical withstand of OLTC.

\section{A. Simulation studies for the OLTC operation}

In this section, the OLTC model will be implemented which utilizes the arc modeling principle inferred from the $\mathrm{CB}$ arc models as noted in section II. Each switching operation of the OLTC is separately simulated with the generalized Cassie-Mayr arc model.

Fig. 7 illustrates the currents and voltages of the OLTC MSCs and TCs. The OLTC starts its operation at time zero and the MSC1 opens at $8 \mathrm{~ms}$ with the TC1 already closed at $4 \mathrm{~ms}$ as seen in Fig. 7(a). In the next step, the TC2 closes at $27 \mathrm{~ms}$ and the TC1 opens at $33 \mathrm{~ms}$ as depicted in Fig. 7(b). The formation of circulating current is the most 
critical part of the tap-changing procedure which occurs between $27 \mathrm{~ms}$ and $33 \mathrm{~ms}$ as shown in Fig. 7(c). Finally, the MSC2 closes at $51 \mathrm{~ms}$ and the TC2 opens at $55 \mathrm{~ms}$ which means one step tap-changing operation has been completed as illustrated in Fig. 7(d). The arcing powers of the MSC1 and MSC2 are negligible as it can be easily inferred from Fig 7 (i.e., the arcing power only exist when the both arcing current and voltage signals are non-zero). The current and voltage signals obtained in this figure are highly in accordance to the real operation logic of OLTCs.

However, the arcing powers calculated for the TC1 and TC2 are considerable. The contributions of the TC1 and TC2 to the total arcing power are $63.43 \%$ and $36.53 \%$, respectively. This was expected as the actual tap-changing operation is carried out by the TCs, not the MSCs. The interruption of circulating current is also performed by the TCs (bridging position).
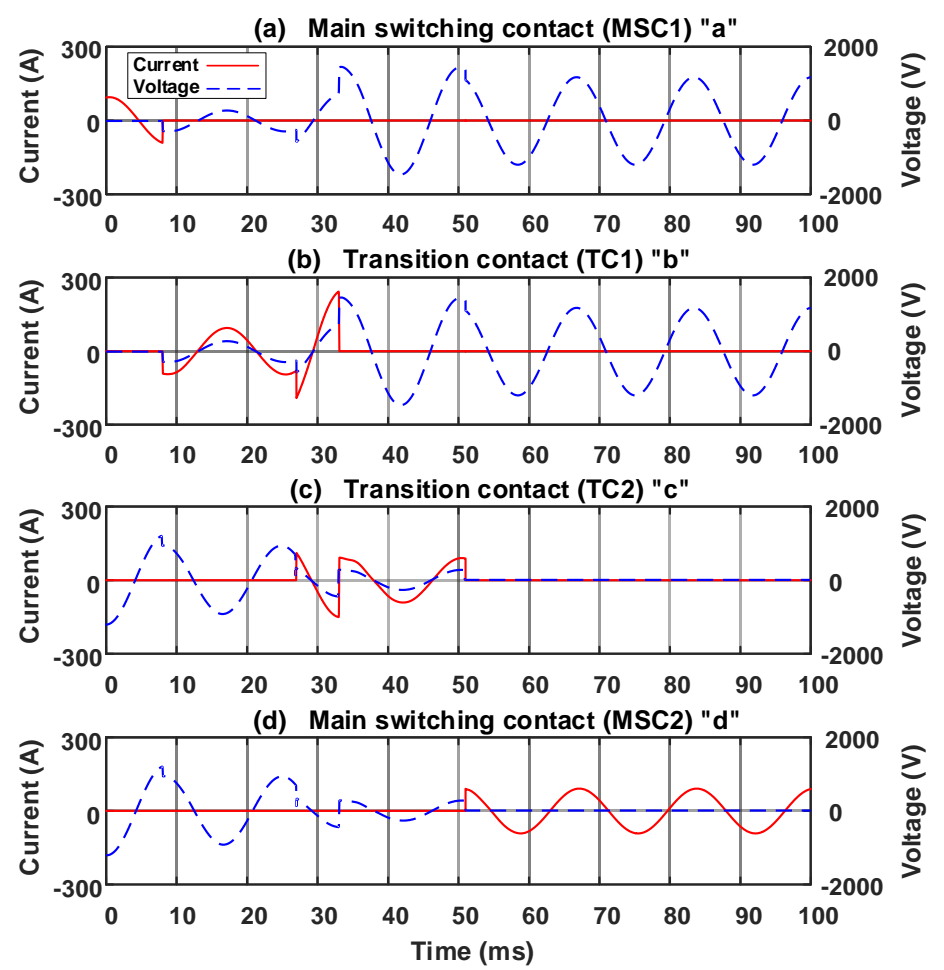

Fig. 7. Instantaneous currents and voltages of the OLTC's MSCs and TCs during one step tap-changing operation.

Figs. 8(a) and 8(b) illustrate the arcing powers of the TC1 and TC2. Total arcing power of the MSCs and TCs and the filtered total arcing power are seen in Fig. 8(c) and $8(d)$, respectively. The total arcing energy related to the filtered arcing power is shown in Fig. 8(e). The arcing energy associated to one tap-changing operation is $1.058 \mathrm{kVA} . \mathrm{s}$ as depicted in Fig. 8(e). The power estimation of OLTC's contacts can only be realized 
using simulation studies as done in this section, because the OLTC terminals are inside the transformer tank immersed in oil and thus inaccessible in practical situations.
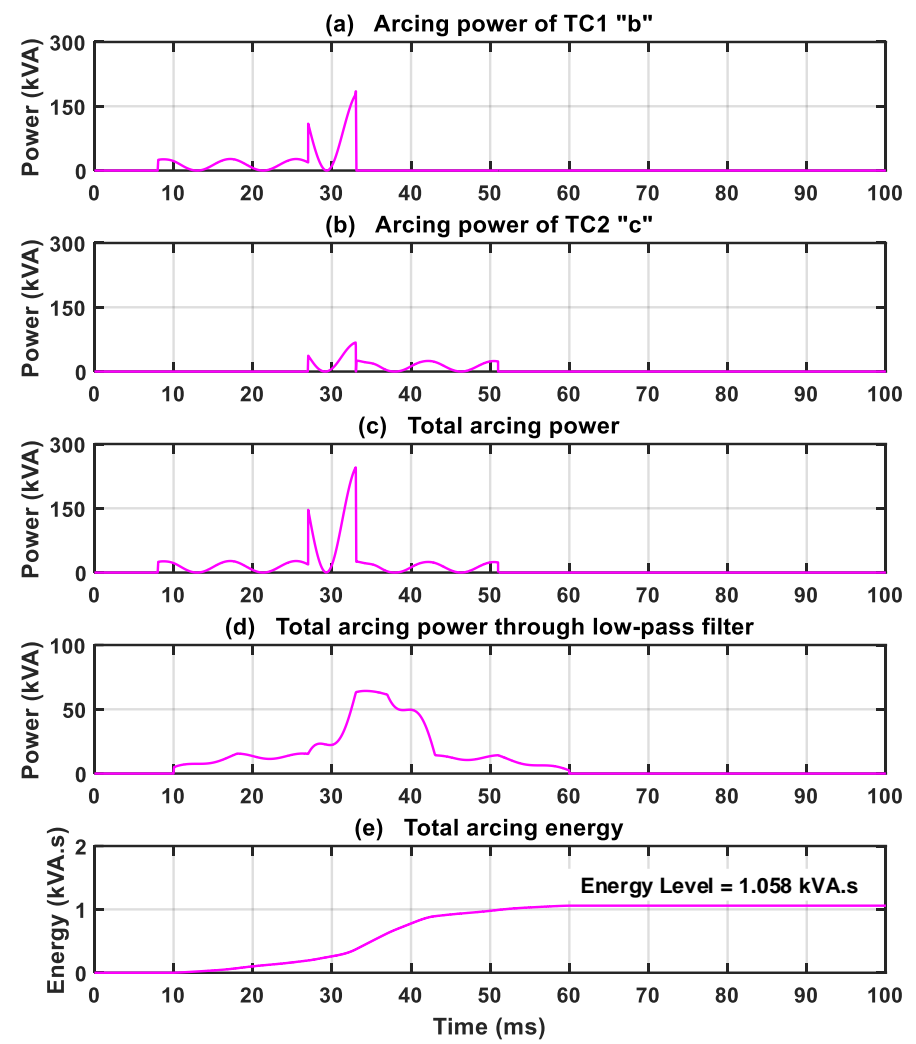

Fig. 8. Arcing powers of the TC1 and TC2, total arcing power of the OLTC's MSCs and TCs, filtered power, and total arcing energy for one step tap-changing operation under the system rated loading.

\section{B. Simulation studies for the OLTC condition monitoring}

This section contains the performance analysis of the $\mathrm{CM}$ algorithm using simulation studies. In this regard, four case studies associated to one step tap-changing operation under the system rated loading and different current levels of OLTC will be considered.

The instantaneous power loss of transformer is estimated by the no-load and full-load test quantities. The active and reactive power losses with respect to the no-load and fullload tests are listed in Table 1. Thus, the instantaneous power loss of the main power transformer can be calculated using equation (9).

As noted earlier, the modeled OLTC is capable of performing 80,000 tap-changing operations without requiring any inspection or maintenance. This amount of operation relates to the mechanical wear of OLTC's contacts that is constant for each tapchanging operation. However, the electrical wear of OLTC's contacts is a function of transformer load current under different operating conditions. Thus, the CM threshold value can be calculated using equation (13) which is about 11 MVA.s as stated before. 
This value will be used to calculate the number of permissible operations related to various tap-changing currents and powers.

Figs. 9(a) and 9(b) display respectively the instantaneous differential power and the estimation of instantaneous power loss of the main transformer feeding the distribution system during tap-changing operation under the system rated loading. The total arcing power of OLTC is calculated by subtracting the transformer estimated power loss from its instantaneous differential power as seen Fig. 9(c). The moving average of total arcing power shown Fig. 9(d) is used to estimate the arcing energy associated to one tap-changing operation which is 1.029 kVA.s in this case and illustrated in Fig. 9(e).

(a) Instantaneous differential power
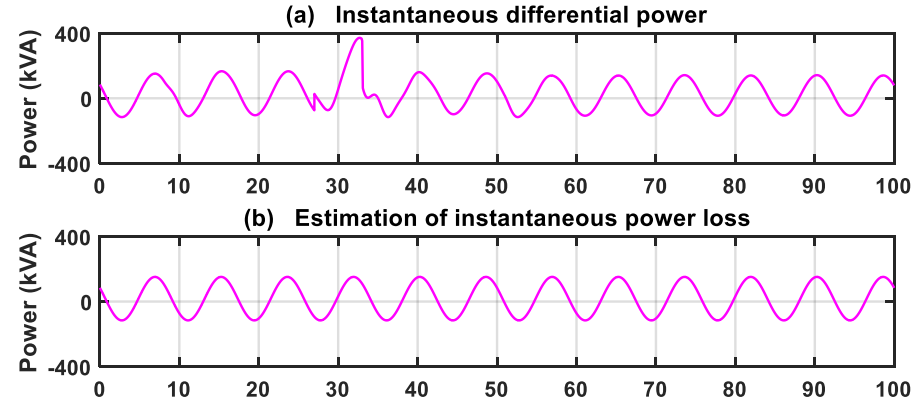

(c) Total arcing power
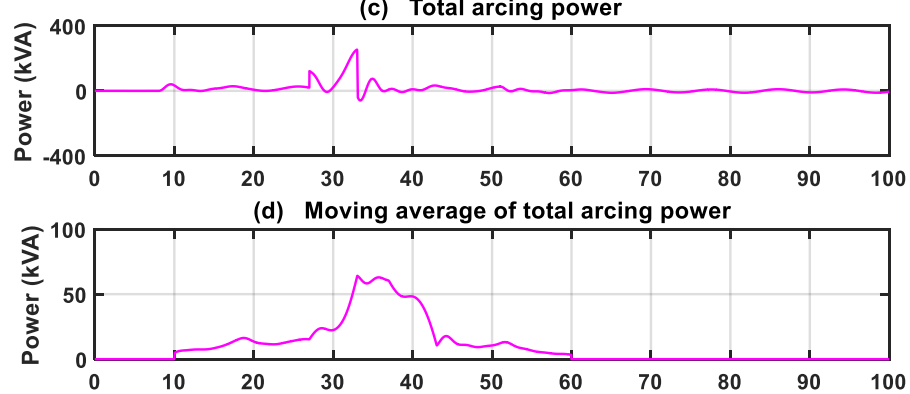

(e) Total arcing energy

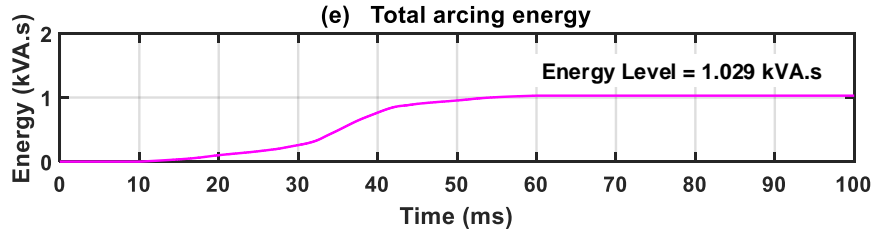

Fig. 9. Response of the CM algorithm for a tap-changing operation under the system rated loading.

The comparison between the energy levels in Fig. 8(e) and Fig. 9(e) demonstrates that the arcing energy calculated across the terminals of OLTC's contacts (i.e., $1.058 \mathrm{kVA} . \mathrm{s}$ ) is highly in accordance to the total arcing energy obtained from the proposed algorithm (i.e., 1.029 kVA.s). The latter case can be implemented practically.

This is a significant finding as it reveals the arcing energy initiated by the OLTC tapchanging operation using an indirect measurement technique (i.e., measuring power difference between the input and output terminals of tap-changing transformer). This is 
also an extremely valuable outcome, because most of OLTCs are inside the power transformer tanks and immersed in oil as noted earlier. Consequently, the direct measurement of OLTC's arcing power using the voltage and current signals of OLTC's MSCs and TCs is practically impossible.

Figs. 10(a), 10(b), and 10(c) illustrate the total arcing power, moving average of arcing power and arcing energy of the main transformer feeding the test system during tap-changing operation under the maximum rated through current of OLTC as noted in Table 2 (or the maximum rated step capacity of OLTC as mentioned in Table 2). In this case, the arcing energy has been calculated as $11.735 \mathrm{kVA} . \mathrm{s}$ which is only $0.00127 \%$ of the $\mathrm{CM}$ threshold value. In this case, after 80,000 tap-changing operations, the inspection or maintenance of OLTC contacts becomes necessary as seen in Table 4.
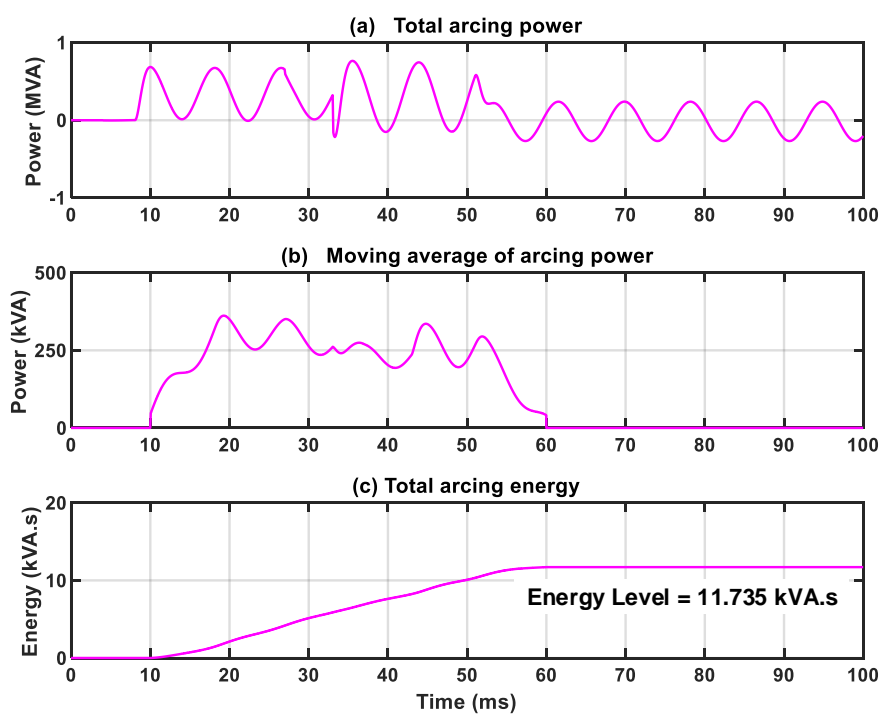

Fig. 10. Response of the CM algorithm for a tap-changing operation under the maximum rated through current of OLTC.

Figs. 11(a), 11(b), and 11(c) illustrate the total arcing power, moving average of arcing power and arcing energy of the main transformer feeding the test system during tap-changing operation under the rated short-time withstand current of OLTC as listed in Table 2. In this case, the related energy has been calculated as $2314.1 \mathrm{kVA} . \mathrm{s}$ which is about $21 \%$ the CM alarm value. In this situation, the inspection or maintenance of OLTC becomes essential only after 2 tap-changing operations as indicated Table 4.

Figs. 12(a), 12(b), and 12(c) illustrate the total arcing power, moving average of arcing power and arcing energy of the main transformer feeding the test system during tap-changing operation under a phase-phase short circuit faulty operation. In this case, 
the internal failure of OLTC will lead to the continuation of arc phenomena and thus the moving average of arcing power never goes to zero as illustrated in Fig. 12(b) which means the total arcing energy always increases as seen in Fig. 12(c). This is a dangerous situation and therefore must be detected in a timely manner in order to prevent a catastrophic failure of the OLTC and consequently the entire power transformer unit. In this regard, a comprehensive study is required to evaluate the existing protection schemes of OLTCs and power transformers. The protection relays must be capable of detecting a continuous arcing condition within millisecond range and a trip signal should be issued immediately when a fault is identified.
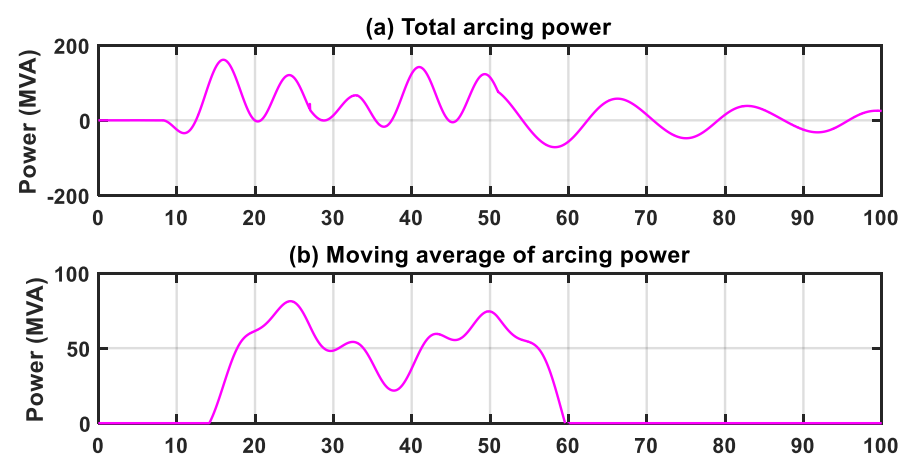

(c) Total arcing energy

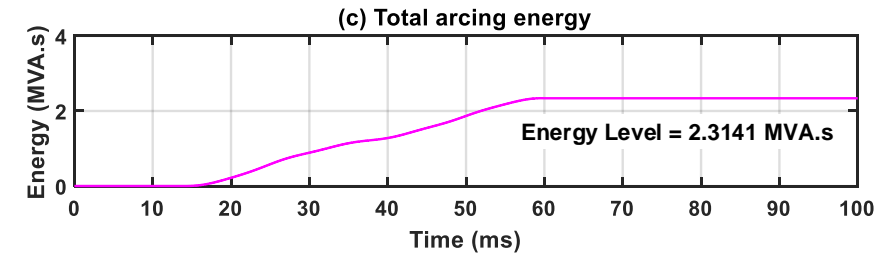

Fig. 11. Response of the $\mathrm{CM}$ algorithm for a tap-changing operation under the rated short-time withstand current of OLTC.
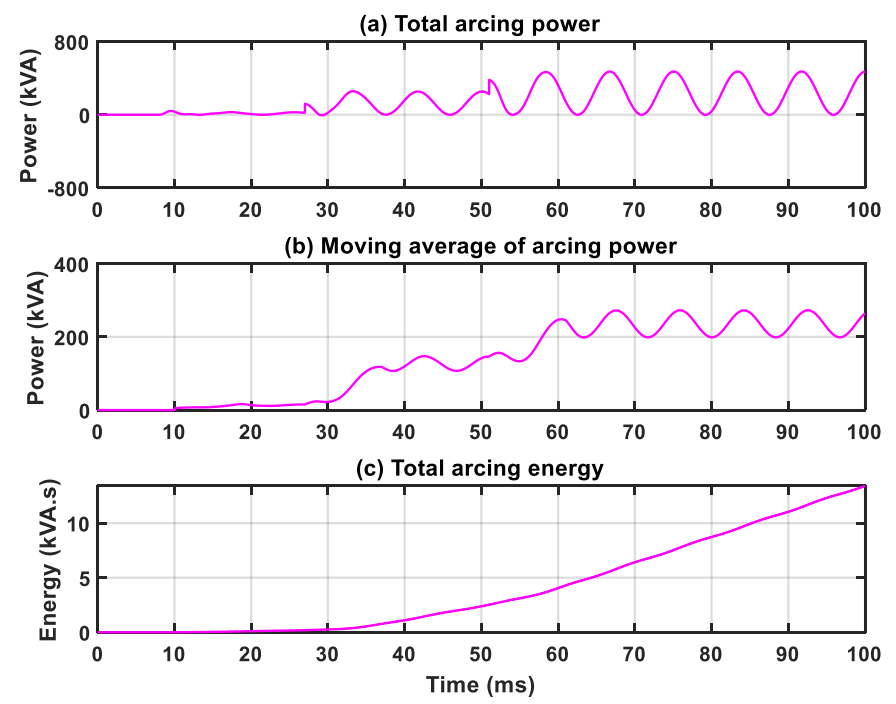

Fig. 12. Response of the $\mathrm{CM}$ algorithm for a tap-changing operation under a faulty operation due to an internal failure of OLTC. 
Finally, considering the proposed CM method, the number of permissible tapchanging operations for different levels of load currents and powers is calculated using equation (14). Table 4 lists the number of permissible operations versus the arcing energies associated to various tap-changing currents and powers of OLTC.

This table shows the comparison results of the number of permissible tap-changing operations with respect to different current, power, and arcing energy values. As mentioned before, the existing CM method provides a constant value which is only based on the number of tap-changing operations without considering the effect of different loading conditions that transformers usually encounter. For instance, the number of permissible tap-changing operation for the studied OLTC is 80,000. However, this number is only valid if the transformer always works under nominal loading condition (i.e., $350 \mathrm{~A}$ and $525 \mathrm{kVA}$ ), but in practical situations, transformer loadings are always changing and therefore the constant counting algorithm cannot exactly represent the condition of OLTC's contact wear.

Table 4: Number of permissible operations for various arcing energies related to different tap-changing

\begin{tabular}{cccc}
\hline $\begin{array}{c}\text { Current } \\
(\mathbf{k A})\end{array}$ & $\begin{array}{c}\text { Power } \\
\text { (MVA) }\end{array}$ & $\begin{array}{c}\text { currents and powers } \\
\text { Arcing Energy } \\
\text { (MVA.s or MJ) }\end{array}$ & $\begin{array}{c}\text { Number of } \\
\text { Operations }\end{array}$ \\
\hline 0.35 & 0.525 & 0.011735 & 80000 \\
0.40 & 0.600 & 0.014847 & 49978 \\
0.45 & 0.675 & 0.019133 & 30095 \\
0.50 & 0.750 & 0.023824 & 19410 \\
0.55 & 0.825 & 0.028924 & 13169 \\
0.60 & 0.900 & 0.034631 & 9186 \\
0.65 & 0.975 & 0.040408 & 6747 \\
0.70 & 1.050 & 0.046776 & 5035 \\
0.75 & 1.125 & 0.053925 & 3789 \\
0.80 & 1.200 & 0.060928 & 2968 \\
0.85 & 1.275 & 0.069222 & 2299 \\
0.90 & 1.350 & 0.077267 & 1845 \\
0.95 & 1.425 & 0.086501 & 1472 \\
1.00 & 1.500 & 0.095563 & 1206 \\
2.00 & 3.000 & 0.433070 & 59 \\
3.00 & 4.500 & 0.935710 & 13 \\
4.00 & 6.000 & 1.575950 & 4 \\
5.00 & 7.500 & 2.314150 & 2 \\
\hline$* E_{\text {thre }}($ threshold value $)$ is initially determined as: $80000 \times(0.011735)^{2}=11.016818$ MVA.s.
\end{tabular}

The proposed arcing power-based algorithm continuously and accurately calculates the number of permissible tap-changing operations based on different loading conditions. In this way, as the value of transformer loadings increases, the number of permissible tap-changing operations decreases. Using this method, the exact time of the 
inspection or maintenance of OLTC's contacts and/or the oil replacement time will be determined.

Fig. 13 illustrates the corresponding CM curve in logarithmic scales. The results obtained from computer simulation studies show that the proposed arcing power-based $\mathrm{CM}$ algorithm provides more accurate and reliable estimations of the electrical wear of OLTC's contacts and thus maintenance or inspection schedules compared to constant counting-based algorithm, because it considers both changes in the arcing voltage and current of OLTC simultaneously. This figure visualizes the number of permissible tapchanging operations versus various loading powers. The CM curve sharply decreases by increasing the tap-changing power values. These results are in accordance to our expectations because the quantity and severity of electric arcs within the OLTC contacts increases by higher values of powers that the tap-changing transformer delivers.

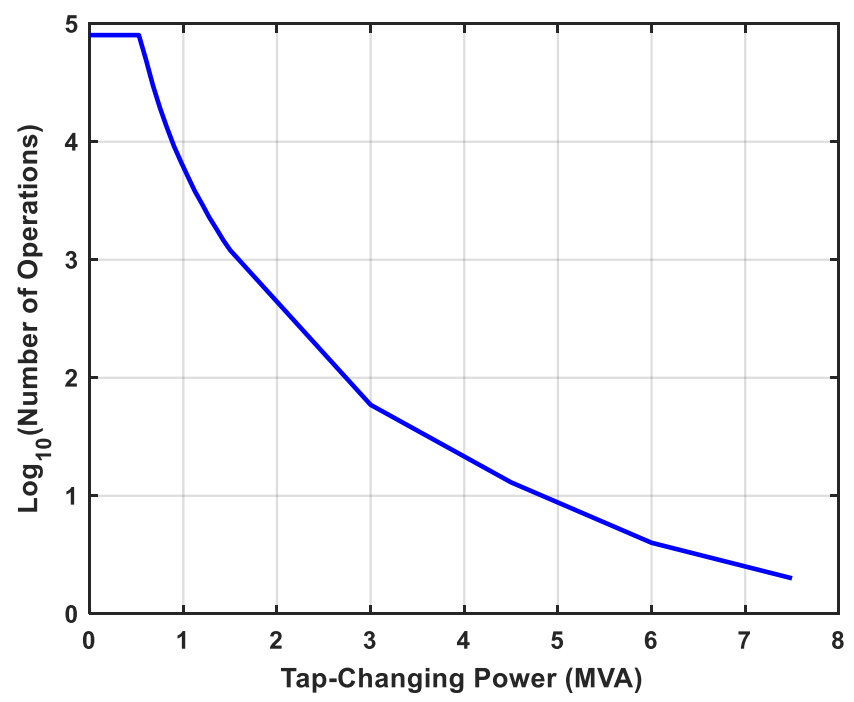

Fig. 13. Number of permissible operations of OLTC (i.e., without requiring the inspection or maintenance of OLTC's contacts) versus different tap-changing powers.

\section{Real-Time Test Studies of the OLTC Operation}

Real-time experiments for the OLTC operation are performed in order to verify and validate the performance of the proposed OLTC model. The same OLTC with technical specifications mentioned in Table 2 is used for the real-time tests. The voltages across the terminals of OLTC's TCs and the currents passing through these contacts have been measured for the performance analysis of the proposed model. The measurement period is taken as $100 \mathrm{~ms}$ and the sampling step is $20 \mu \mathrm{s}$, therefore the sampling frequency of the data acquisition system is $50 \mathrm{kHz}$. The system frequency of the experimental setup 
is $50 \mathrm{~Hz}$. The window length of the applied moving average filter is considered $8 \mathrm{~ms}$ that contains 400 samples relating to the sampling frequency.

Fig. 14 shows the experimental setup used for the OLTC operation tests. The power supply unit is used to feed the input terminal of OLTC's TC contacts with the capability of delivering the OLTC rated current. The resistive loads are connected to the output terminal of OLTC's TC contacts. A three-phase power supply unit is used to feed the motor drive mechanism of OLTC. A Rogowski coil current clamp sensor is used to measure the instantaneous current passing through the TC contacts. On the other hand, a differential voltage probe is used to measure the instantaneous voltage across the terminals of TC contacts. A digital oscilloscope is used to capture the instantaneous values of voltage and current signals from the measurement sensors at the same time. Finally, a personal computer is used to store the real-time voltage and current signals to calculate the arcing power.

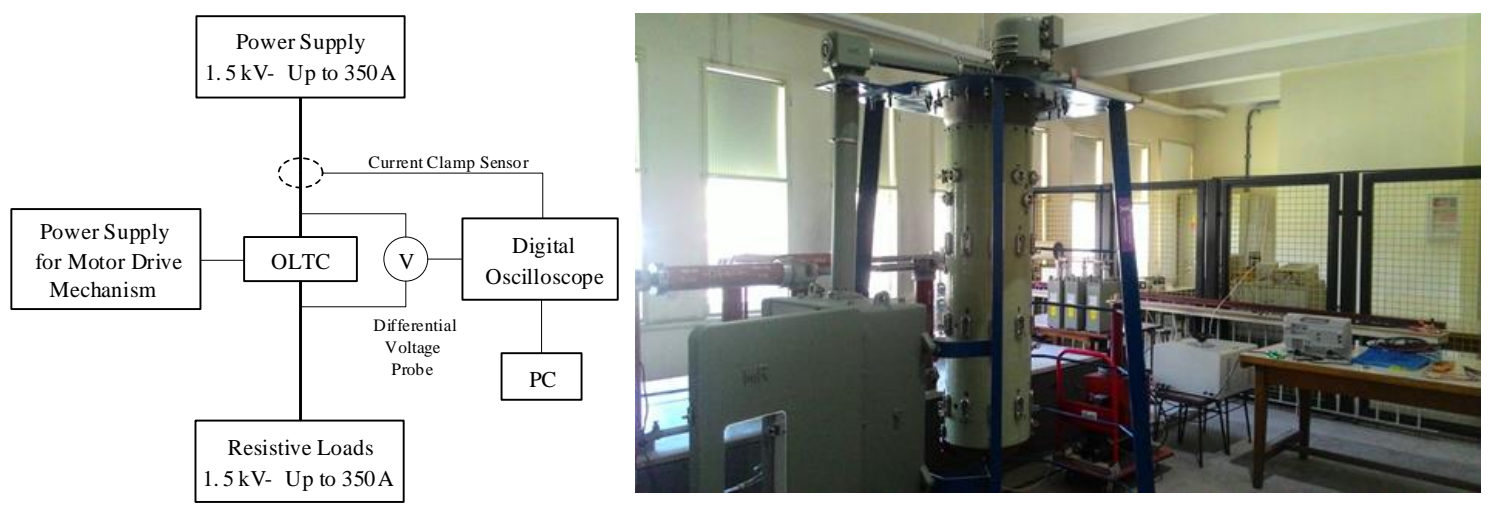

Fig. 14. Experimental setup for the OLTC operation tests.

Figs. 15(a) and 15(c) illustrate the instantaneous currents and voltages of the OLTC's TC1 and TC2 during one-step tap-changing operation. Figs. 15(b) and 15(d) show the arcing powers of the OLTC's TC1 and TC2. The contributions of the OLTC's TC1 and TC2 to the total arcing power are $53.78 \%$ and $46.22 \%$, respectively.

The OLTC operation starts at $17 \mathrm{~ms}$ to change tap position. The voltage across the TC1 starts to appear at the same time which takes about $35 \mathrm{~ms}$ to completely recover as seen in Fig. 15(a). On the other hand, the voltage across the TC2 starts to vanish at $48 \mathrm{~ms}$ and takes about $35 \mathrm{~ms}$ to completely go to zero as depicted in Fig. 15(c). The entire process which involves the operation of TC1 and TC2, changes the OLTC position from one step to another. The circulating current flows for $4 \mathrm{~ms}$ from $48 \mathrm{~ms}$ to 
$52 \mathrm{~ms}$ which is the current going through the both TCs at the same time. This is close to the results obtained from simulation studies which showed a $6 \mathrm{~ms}$ flow of circulating current. Clearly, the real-time arcing power of TC1 in Fig. 15(b) follows the same trend as the arcing power obtained from simulation studies as shown in Fig. 8(a). On the other hand, the real-time arcing power of TC2 in Figure 10.3(d) is very similar to that obtained from simulation studies as illustrated in Fig. 8(b).
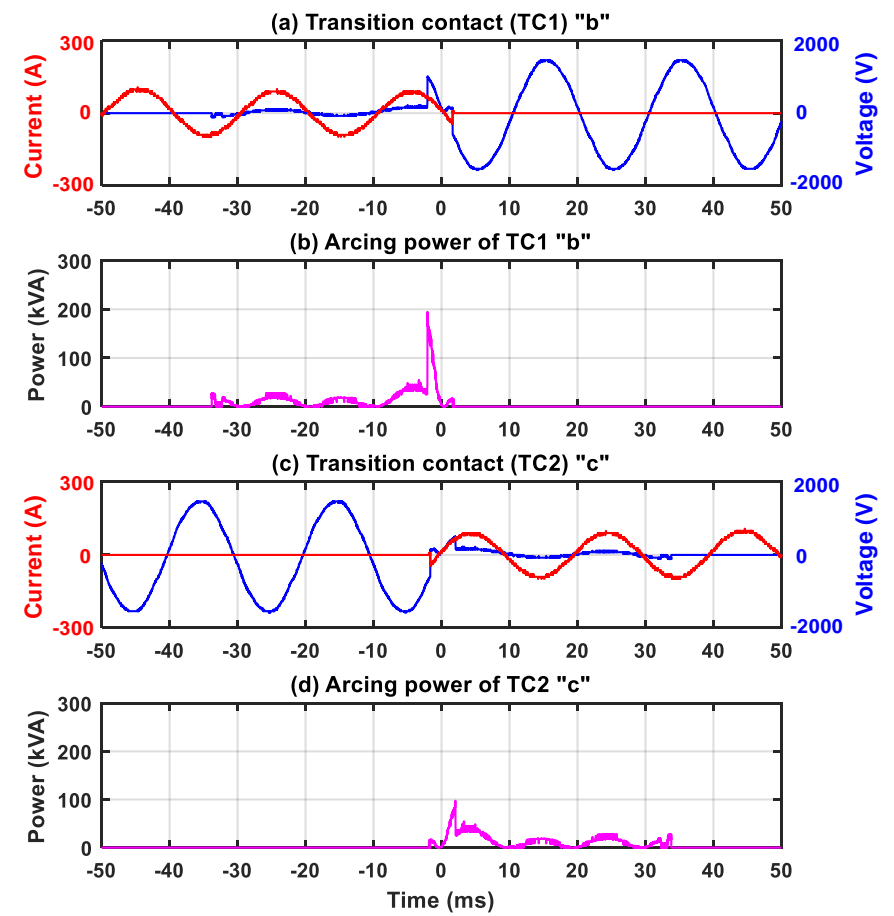

Fig. 15. Instantaneous currents, voltages, and powers of the OLTC's TCs during one step tap-changing operation obtained from real-time tests.

Fig. 16(a) shows the total arcing power related to both TCs of OLTC for one-step tapchanging operation. The real-time arcing power is in accordance to the one obtained from simulation studies as seen in Figure 8(c). Figs. 16(b) and 16(c) show the real-time total arcing power through a moving average filter and total arcing energy.

The total arcing energy of real-time test studies is calculated as $1.1007 \mathrm{kVA} . \mathrm{s}$ as it is shown in Figure 16(c) which is in accordance to the total arcing energy obtained from the simulation studies (1.058 kVA.s) as illustrated in Fig. 8(e).

In this section, the real-time test studies for the OLTC operation has been performed. The instantaneous voltage across the terminals of OLTC's TCs and the instantaneous current going through TCs have been measured to calculate the OLTC arcing power. The obtained voltage and current signals measured from the terminals of OLTC's TCs in 
the real-time test studies verify and validate those voltage and current waveforms obtained from the OLTC model using the simulation studies. Furthermore, the total estimated arcing power of TCs taken from experiments is in conformity with what was calculated before in the simulation studies. Therefore, the performance of the proposed OLTC model is successfully validated using the real-time test studies.
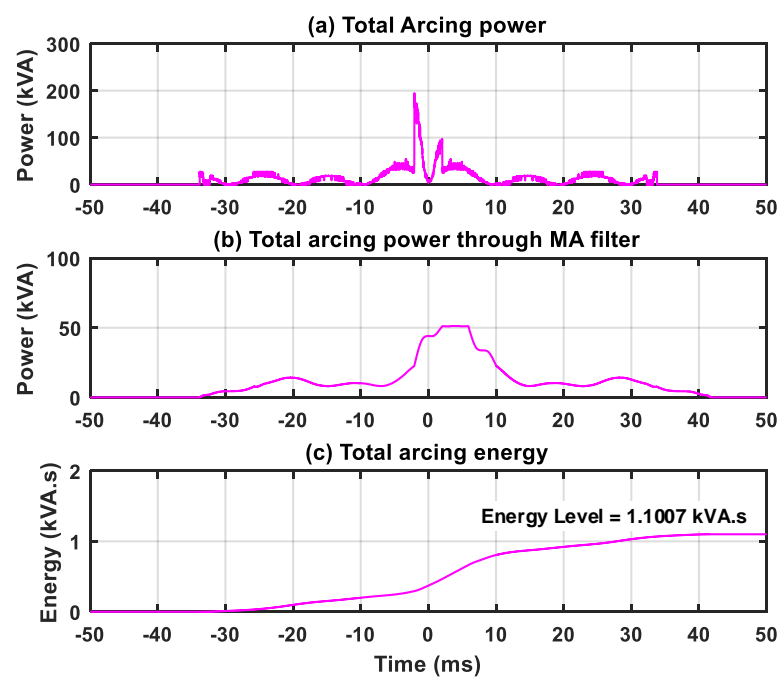

Fig. 16. Total arcing power of the OLTC's TCs, filtered power, and total arcing energy for one step tapchanging operation under the system rated loading obtained from real-time tests.

\section{Discussions and Conclusions}

This paper proposes an original modeling concept for OLTCs based on the existing $\mathrm{CB}$ arc models and also introduces a novel $\mathrm{CM}$ algorithm that utilizes the instantaneous differential power of transformers to calculate the OLTC arcing power and its related arcing energy for determining the inspection or maintenance times of OLTC contacts.

The CM procedure has been realized utilizing the cumulative arcing energy of OLTC operations. Whenever the accumulated arcing energy reaches the CM threshold value, it indicates that the maximum contact wear of OLTC's arcing contacts has been reached and hence the inspection or maintenance alarm signal is initiated to inform the system operator. The results obtained from simulation studies prove that the proposed CM algorithm is perfectly capable of evaluating the degradation level of OLTC's contacts. The measured results from the real-time test studies verify and validate the performance of the proposed OLTC model.

Other mechanical issue such as looseness of springs, coking on switches and contacts, defects of motor drive mechanism, and misalignments of contacts can increase the 
arcing time of tap-changing operations. This will generate a higher arcing energy and therefore a higher electrical wear of OLTC contacts. By considering the cumulative arcing energy, the algorithm takes the effects of these issues into account as well. The findings of this research are mentioned in the following items.

- An original OLTC model has been introduced that benefits from the arc modeling concepts of CB.

- A new arcing power-based algorithm is introduced that estimates the electrical wear of OLTC's contacts for estimating the OLTC inspection or maintenance times.

- The proposed algorithm uses the instantaneous differential power between the input and output terminals of transformer to calculate the arcing power of OLTC's contacts. This is highly valuable because the direct power measurements of OLTC's contacts are impossible due to accessibility issues.

- The arcing power measurement considers both changes in the arcing current and voltage of OLTC that provides more accurate estimations of the degradation level of OLTC contacts and thus their inspection or maintenance schedules.

- The proposed algorithm uses the OLTC arcing powers that solely exist during tapchanging conditions and hence the measurement does not require to be synchronized to power system frequency. This is an advantage of the proposed algorithm because a successful time/frequency synchronization requires an advanced filtering and hence a higher computation time.

- The moving average filter used in the algorithm effectively removes the high frequency components of arcing power to provide more smooth and reliable signals for the proposed algorithm.

\section{Acknowledgment}

The authors would like to express their sincere gratitude and appreciation to Maschinenfabrik-Reinhausen (MR) GmbH from Germany for providing an OLTC to the high-voltage laboratory of Istanbul Technical University. We are especially grateful to $\mathrm{C}$. Fuchs from MR for the installation of OLTC and sharing his extensive technical experiences with us. 


\section{References}

[1] IEEE Standard Requirements for Tap Changers, C57.131, May 2012.

[2] Transformer Reliability Survey, CIGRÉ WG A2.37, ELECTRA, 2016.

[3] D. Martin, J. Marks, T. Saha., "Survey of Australian power transformer failures and retirements," IEEE Electrical Insulation Magazine, vol. 33, no. 5, pp. 16-22, 2017.

[4] M. F. Lachman, "Field Measurements of Transformer Single-Phase Exciting Current as a Diagnostic Tool, and Influence of Load Tap Changers," IEEE Trans. Pow. Del., vol. 9, no. 3, pp. 1466-1475, Jul. 1994.

[5] H. Wang, Y. Liu, P. J. Griffin, "Artificial Intelligence in OLTC Fault Diagnosis Using Dissolved Gas-In-Oil Information, Proc. of IEEE Power Engineering Society Summer Meeting, pp. 24222427, Jul. 2000.

[6] P. Kang and D. Birtwhistle, "Condition Assessment of Power Transformer On-Load TapChangers Using Wavelet Analysis," IEEE Trans. Pow. Del., vol. 16, no. 3, pp. 394-400 , Jul. 2001.

[7] L. A. L. de Almeida, M. Fontana, F. A. Wegelin and L. Ferreira, "A New Approach for Condition Assessment of On-Load Tap-Changers using Discrete Wavelet Transform," 2005 IEEE Instrument. and Measurement Technology Conference Proceedings, Ottawa, Ont., 2005, pp. 653656.

[8] T. Kohonen, Self-organising maps: Springer, third edition, 1997.

[9] P. Kang and D. Birtwhistle, "Condition monitoring of power transformer on-load tap-changers. Part 1 : Automatic condition diagnostics," IEE Proc-Gener. Transm. Distrib., vol. 148, no. 4, pp. 301-306, Jul. 2001.

[10] P. Kang and D. Birtwhistle, "Condition Assessment of Power Transformer On-Load TapChangers Using Wavelet Analysis and Self-Organizing Map: Field Evaluation," IEEE Trans. Pow. Del., vol. 18, no. 1, pp. 78-84, Jan. 2003.

[11]E. Rivas, J. C. Burgos, and J. C. García Prada, "Condition Assessment of Power OLTC by Vibration Analysis Using Wavelet Transform," IEEE Trans. Pow. Del., vol. 24, no. 2, pp. 687694 , Apr. 2009.

[12]E. Rivas, J. C. Burgos, and J. C. García Prada, "Vibration Analysis Using Envelope Wavelet for Detecting Faults in the OLTC Tap Selector," IEEE Trans. Pow. Del., vol. 25, no. 3, pp. 16291636, Jul. 2010.

[13]X. Zhou and F. H. Wang, "Research on chaotic dynamic characteristics of onload tap changers," 2014 IEEE PES General Meeting Conference \& Exposition, National Harbor, MD, 2014, pp. 1-5.

[14] Ruochen Duan and Fenghua Wang, "Mechanical condition monitoring of on-load tap-changers using chaos theory \& fuzzy C-means algorithm," 2015 IEEE Power \& Energy Society General Meeting, 2015, pp. 1-5.

[15]X. Hu, Y. Duan, J. Yong, "Fuzzy diagnostics for mechanical fault of on-load tap changers," Advanced Materials Research, vol. 1092, pp. 272-275, 2015.

[16] R. Esteller, G. Vachtsevanos, J. Echauz and B. Litt, "A comparison of waveform fractal dimension algorithms," IEEE Trans. on Circuits and Systems I: Fundamental Theory and Applications, vol. 48, no. 2, pp. 177-183, Feb 2001.

[17] A. Secic and I. Kuzle, "On the novel approach to the On Load Tap Changer (OLTC) diagnostics based on the observation of fractal properties of recorded vibration fingerprints," IEEE EUROCON 2017 -17th International Conference on Smart Tech., Ohrid, 2017, pp. 720-725.

[18]E. F. Simas F., L. A. L. de Almeida and A. C. de C. Lima, "Vibration Monitoring of On-Load Tap Changers Using a Genetic Algorithm," 2005 IEEE Instrumentation and Measurement Tech. Conference Proceedings, Ottawa, Ont., 2005, pp. 2288-2293.

[19] Q. Li, T. Zhao, L. Zhang and J. Lou, "Mechanical Fault Diagnostics of Onload Tap Changer Within Power Transformers Based on Hidden Markov Model," IEEE Trans. Pow. Del., vol. 27, no. 2, pp. 596-601, April 2012.

[20] R. Duan and F. Wang, "Fault Diagnosis of On-Load Tap-Changer in Converter Transformer Based on Time-Frequency Vibration Analysis," IEEE Trans. on Indust. Electr., vol. 63, no. 6, pp. 38153823, June 2016.

[21] J. Seo, H. Ma and T. K. Saha, "A Joint Vibration and Arcing Measurement System for Online Condition Monitoring of Onload Tap Changer of the Power Transformer," IEEE Trans. Pow. Del., vol. 32, no. 2, pp. 1031-1038, April 2017. 
[22] J. J. Erbrink, E. Gulski, J. J. Smit, P. P. Seitz, B. Quak, and R. Leich, "On-load tap changer diagnosis - an off-line method for detecting degradation and defects: Part 1," IEEE Electrical Insulation Magazine, vol. 26, no. 5, pp. 49-59, September-October 2010.

[23] J. J. Erbrink, E. Gulski, J. J. Smit, R. Leich, B. Quak and R. A. Malewski, "On-load tap changer diagnosis-an off-line method for detecting degradation and defects: part 2," IEEE Electrical Insulation Magazine, vol. 27, no. 6, pp. 27-36, November-December 2011.

[24] A. G. Deakin, J. W. Spencer, D. H. Smith, D. Jones, N. Johnson and G. R. Jones, "Chromatic Optoacoustic Monitoring of Transformers and Their Onload Tap Changers," IEEE Trans. Pow. Del., vol. 29, no. 1, pp. 207-214, Feb. 2014.

[25] N. Abeywickrama, O. Kouzmine, S. Kornhuber, L. Cheim, P. Lorin, and M. Gauvin, “Application of novel algorithms for continuous bushing and OLTC monitoring for increasing network reliability," CIGRE, vol. A2, no. 113, 2014.

[26]B. Feizifar, O. Usta, "A Novel Arcing Power-Based Algorithm for Condition Monitoring of Electrical Wear of Circuit Breaker Contacts," IEEE Trans. Pow. Del., 2018, under revision.

[27]M. A. Redfern, O. Usta and G. Fielding, "Protection against loss of utility grid supply for a dispersed storage and generation unit," IEEE Trans. Pow. Del., vol. 8, no. 3, pp. 948-954, Jul. 1993.

[28] M. A. Redfern and M. J. Checksfield, "A new pole slipping protection algorithm for dispersed storage and generation using the equal area criterion," IEEE Trans. Pow. Del., vol. 10, no. 1, pp. 194-202, Jan. 1995.

[29] O. Usta, M. Bayrak and M. A. Redfern, "A new digital relay for generator protection against asymmetrical faults," IEEE Trans. Pow. Del., vol. 17, no. 1, pp. 54-59, Jan 2002.

[30]B. Khodabakhchian, "Modeling On-Load Tap Changers In EMTP-RV," EMTP-RV Newsletter, vol. 1, no. 1, Nov. 2005.

[31] G. Sybille, "SimPower Systems Toolbox 7.3," Mathworks Inc., 2006.

[32] A. M. Cassie, "Arc rupture and circuit severity: A new theory, " in CIGRE, Report No. 102, 1939.

[33] O. Mayr, "Beitraege zur Theorie des statischen und dynamischen Lichtbogens", Archiv fur Elektrotechnik 37(H12), S588-S608, 1943.

[34] U. Habedank, "Application of a new arc model for the evaluation of short-circuit breaking tests," IEEE Trans. Pow. Del., vol. 8, no. 4, pp. 1921-1925, Oct 1993.

[35] E. Haginomori, T. Koshiduka, et. al., "Power System Transient Analysis: Theory and Practice using Simulation Programs (ATP-EMTP)," John Wiley \& Sons, Ltd., 2016, pp. 105-130.

[36]L. Dubé and H.W. Dommel, "Simulation of control systems in an electromagnetic transients program with TACS," Proc. IEEE PICA Conf., pp. 266-271, May 1977.

[37] Technical note, Transformer / line loss calculations, Schneider Electric, 70072-0153-08, 2011.

[38] M. A. Redfern, O. Usta, G. Fielding and E. P. Walker, "Power based algorithm to provide loss of grid protection for embedded generation," IEE Proceedings - Generat., Transmission \& Distribution, vol. 141, no. 6, pp. 640-646, Nov 1994.

[39] S. Subramanian and A. Varghese, "Condition Monitoring and Protection," Protection, Automation and Control World Magazine, Sep. 2011.

[40] R. Abu-Hashim et al., "Test systems for harmonics modeling and simulation," IEEE Trans. Pow. Del., vol. 14, no. 2, pp. 579-587, Apr 1999.

[41] OILTAP ${ }^{\circledR}$ V III 350 D, on-load tap-changer for regulating transformers, Maschinenfabrik Reinhausen GmbH, IN228/02 EN - 10/11 - F0018002, 2003. [Online]. Available: http://www.reinhausen.com/XparoDownload. ashx?raid=219.

[42] R. Thomas, D. Lahaye,C. Vuik, L. van der Sluis, "Simulation of Arc Models with the Block Modelling Method," Proc. of Int. Conf. on Power System Transients (IPST2015), Cavtat, Croatia, Jun. 2015. 